\title{
Los «beneficia» concedidos a las ciudades de Acaya en el año 66 d.C.
}

\author{
Pilar Fernández Uriel *
}

\begin{abstract}
RESUMEN
ABSTRACT

Situación de las ciudades griegas

durante en Alto Imperio romano y la política faborable de Nerón, análisis de los beneficios concedidos en su viaje a la provincia Acaya.

The Greek citys sitiation in the Roman Empire, and the Nero's favourable politic with the benefits coceded on his travel to the Acaya province.
\end{abstract}

Uno de los momentos más importantes y críticos del período neroniano se iniciaba en el otoño del año 66 , exactamente a finales del mes de septiembre según el relato de Dion Casio (Dion Casio, 63, 8, 4).

Se trataba de un proyecto que Nerón había acariciado y planeado largamente: Su viaje a las ciudades griegas de Acaya. Hasta es posible que este viaje se encontrara incluido en un proyecto mucho más amplio y ambicioso hacia ciertas regiones orientales del Imperio por las que sin duda el césar sentía una especial predilección: Grecia y Egipto.

\section{LAS CIUDADES DE ACAYA}

Julio César convirtió la región griega de Acaya en provincia romana ${ }^{1}$. Aunque abarcaba una de las zonas geográficas más pobres y montañosas

* Departamento de Prehistoria e Historia Antigua. UNED.

Anteriormente el cónsul Q, Lucio Mumio, tras arrasar Corinto y derrotar a la Liga Aquea en el 146 a, C, convirtió a Grecia en la provincia romana de Acaya. Más adelante se desdoblaría en dos provincias: Acaya y Macedonia. Ver ROMER, F. E.: "Gaius Caesar 's Military Diplomacy in the East", TAPA, 109, 1979, págs. 199-214; Sobre las provincias de Acaya y Macedonia en época romana ver TEMPORINI, H.; HASE, W ed.: Aufstieg und Niedergang des römischen Welt. N. York-Berlín, II. 7. 1. 1979. 
de la península Balcánica, se encontraban en ella importantes y antiguas Poleis, centros de la tradición histórico-cultural de Grecia.

Su situación administrativa era sumamente compleja. Se organizaban estas ciudades en Koina locales, a modo de estructura federal que reconoció Calígula (I. G., 2711). Algunas de estas ligas participaban en un Koinon panaqueo y otras no ${ }^{2}$. Entre los años 27 al 9 a. C., probablemente se establecieron las modificaciones necesarias para dotar a Acaya como provincia senatorial romana que, como tal, reunía las regiones situadas al sur de Tesalia. Era gobernada por un procónsul ex pretor, elegido por sorteo en el Senado, aunque a veces, fue nombrado directamente por el emperador como en el caso de S. Sulpicio Galba.

Una de las características de de la provincia de Acaya era su elevado número de ciudades libres que, en principio, no estaban bajo la autoridad del gobernador romano. Ello causó dificultades en la gestión de la administración provincial e incluso, sublevaciones de características similares a las sucedidas en Atenas en el año $13 \mathrm{~d}$. C.

No parece muy difícii definir los límites entre el antiguo mundo griego y la realidad de la provincia romana de Acaya que, aunque empobrecida, mantenía el recuerdo de sus antiguas y prestigiosas ciudadades.

Ciertamente, Acaya había sufrido mucho en los últimos años de la crisis republicana debido principalmente a las secuelas derivadas de las guerras civiles y a las rivalidades entre las propias ciudades griegas, (invasiones, mantenimiento del ejército en sus tierras, saqueos etc...).

Muchas inscripciones indican las quejas ante las presiones y abusos que sufre la región. Primordialmente éstas consistían en cargas excesivas de impuestos y las reclutaciones de tropas entre sus gentes. Todo ello trajo como consecuencia el empobrecimiento de sus ciudades, el despoblamiento de sus campos, gran parte de ellos explotados por grandes

\footnotetext{
2 Cada ciudad tenía sus propias instituciones. El tipo de instituciones griegas era el más extendido en el Imperio, que era utilizado tanto en Grecia como en las ciudades de Asia Menor. Sus ciudadanos se distribuian por tribus, pero votaban individualmente. La principales instituciones ciudadanas eran el Consejo (Boulé), la asambiea (Ecclesía) y las numerosas magistraturas que solían tener la duración de un año. Sobre la situación administrativa de la provincia Acaya en sus antecedentes administrativos y políticos ver: BERTRAND, J. M.: Cités et royaumes du mond grec: espace et politique. París, 1992; Sobre la época Helenística y romana: OLIVIER, J. H.: "Panacheans and Panhellenes", Hesperia, 47, 1978, págs. 185-191; Sobre la politica de Augusto en dicha provincia: LARSEN, J. A. O.: "The policy of Augustus in Greeece", Acta Classica (Proc. South African Class. Ass.) 1, 1958, págs. 123-130; GroAG, E.: Die römischen Reichsbeamten von Achaia bis auf Diokletian. Viena, 1939; También SARTRE, M.: El Oriente Romano. Madrid, 1994, pág. 220.
} 
propietarios, y la inoperatividad de sus puertos que quedaron indefensos anter las incursiones de los piratas orientales, lo que provocaría la ruina económica de sus artesanos y comerciantes ${ }^{3}$.

Delos, uno de los principales puertos francos, perdió su importancia como tal para no volver a recuperarse ${ }^{4}$.

Autores como Estrabón. Plutarco y Dion de Prusa nos describen un panorama desolador sobre el empobrecimiento y la decadencia de estas ciudades en época romana. Coinciden en señalar como causa principal de ello el despoblamiento de esta región. Además, nos trasmiten un sentimiento de preocupación, asombro y tristeza a la vez ante la contemplación de la decadencia y ruina de estas ciudades griegas que habían tenido un pasado tan célebre y glorioso, digno de ser cantado y trasmitido por sabios y poetas ${ }^{5}$.

\section{LAS CIUDADES}

En Acaya, todo el teritorio provincial pertenecía a las ciudades (Chora), incluso los dominios imperiales, salvo las canteras de Caristos y de Paros ${ }^{6}$. Durante la época helenística la urbanización habia cambiado. No eran ya las mismas ciudades de la época clásica. Algunas, demasiado pequeñas para sobrevivir, se fusionaron en sinecismo, otras desaparecieron, abandonadas o destruidas por las guerras y la dominación romana ${ }^{7}$.

Los propios dominadores romanos se preocuparon de su repoblación y de la fundación de colonias. Las fundaciones más importantes fueron las

3 La presencia de propietarios romanos en las provincias griegas se encuentra atestiguado. Tampoco hay duda de dominios imperiales. Concretamente en el principado de Nerón, el hijo del tirano de Esparta, C. Julio Graco fue procurador imperial encargado de los dominios imperiales en Acaya AE, 19271 y 2; WoODWA RD, A. M.: “Inscriptions from Thessaly and Macedonia", J.H.S., 23, 1913, págs. 337-346.

4 Sobre la situación de Grecia y concretamente de Acaya, durante el dominio romano ver: ACCAME, S., II dominio romano in Grecia dalla arcaica ad Augusto. Roma, 1946, reim, 1972; BENGTSON, H.: "Das politische Leben der Griechen in der römischen Kaiserzeit". Welt als Geschichte, 1950.

5 Estrabón, VIII, 5; Plutarco, De Defectu Oraculorum, 8, 414; Dion de Prusa, VII, 34 y XXXIII, 25, 26. Es notable la insistencia del abandono de los campos en el famoso discurso del cazador-campesino de la obra de Dion de Prusa. Estudiado por DesIDERI, P.: Dione di Prusa. Un intellectuale greco dell'impero romano, Mesina-Florencia, 1978.

6 Sobre las minas y canteras ver LARSEN, J. A. O.: Roman Greece, Los Ángeles, 1970, págs. 461-465.

7 Sobre la enumeración de estas ciudades: KAHRSTEDT, U.: Das wirtschaftlice Gesicht Griechenlands in der Kaiserzeit Kleinstadt, Vila und Domäne. Berna, Francke, 1954, págs. 258-261. 
de Corinto en el año 44 a. C. y la de Patras en el 15 a. C. Estas colonias en Acaya, como en Macedonia estaban destinadas no sólo a proporcionar tierras a los veteranos sino a devolver la vida a estas zonas, tan castigadas por la miseria y las guerras.

Mención especial merece Corinto, ciudad emplazada en el Istmo de su mismo nombre. Fue destruida en el 146 a. C por el cónsul romano Q. Lucio Mumio, cuando derrotó y disolvió la Liga Aquea.

César fundó allí la Colonia Laus Iulia Corinthus, poblándola de itálicos y libertos traídos de Roma.

Lugar magníficamente situado, era nudo de las comunicaciones entre el Peloponeso y las regiones continentales, entre el Golfo Sarónico y el de Corinto, sobre el mar Jonio. Favorecida también por Augusto, fue la capital de la provincia y ocupó el lugar de Delos como principal puerto franco. Fue ciudad cosmopolita e industriosa, donde afluian artesanos y comerciantes de otras parte como egipcios, sirios y judíos ${ }^{8}$.

También sobresalía la ciudad de Dimé, protegida por el propio Augusto que le proporcionó un vasto territorio (Chora) que se extendía no sólo por el noroeste del Peloponeso sino también por la otra orilla del golfo de Corinto.

Dos ciudades fueron igualmente favorecidas por la colonización romana:

Nicópolis, fundada despues de Accio, en torno al santuario de Apolo Acciaco, en cuyo honor se celebraron los juegos de su nombre en agradecimiento por la decisiva intervención del dios. Aunque protegida por Augusto, donándo a la ciudad un importante territorio del cantón epirota, ésta no fue una fundación colonial romana sino considerada como Polis griega y gozó de una gran actividada económica y social, como demuestran sus dos puertos, su teatro, odeón, gimnasio y estadio.

Patras, creada como colonia de veteranos, su territorio se amplió hasta la orilla septentrional del Golfo de Corinto. Junto a Corinto, Patras se convirtió en un centro económico y mercantil.

8 Corinto llegó a ser desde el principado de Augusto una de las ciudades más bulliciosas y prósperas de Grecia. Ello queda atestiguado por sus construciones (Templos de Hera Akraía, Apolo y Afrodita, los pórticos del ágora, las "Tabernae", el mercado norte, las basílicas Sur y Iulia, las fuentes y las ampliaciones del puerto de Cencreas con Tiberio y Claudio, acabadas en época Flavia, así como la construcción del teatro con Nerón. Estas construcciones continuaron en época Antonina. Destacan la actividad de sus puertos y la obra de sus artesanos broncistas cuya fama permaneció a lo largo del Imperio. Sobre la Corinto romana ver: WISEMAN, J.: "Corinth and Rome I, 228 BC-AD 267", ANRW, III, 7, 1, págs. 438-548; MuRPHy O'CONNor, Corinthie au temps de Sain Paul. París, 1986, págs.. Roux, G: Pausanias en Corinthie. París, 1958; también: AmANDRY, M.: Le monnayage des duovirs corinthiens. París, BCH Su, págs., 1988. 
Otras ciudades que merecen especial mención fueron Elatea, Egina, Tanagra, Tespies, Olimpia y Delfos.

A pesar de la prosperidad de Corinto y de los favores concedidos por Roma a estas ciudades de Acaya, buscando su recuperación, entre las que se destaca también Atenas, otras muchas ciudades del Istmo se encontraban en franca decadencia. Pausanias cuenta que Sición estaba despoblada y sus edificios ruinosos. Nemea no era más que un pueblo y Argos se mantenía a duras penas (Pausanias, II, 6-11).

\section{LA RELACIÓN CON ROMA}

Debido, pues, al cierto auge de estas ciudades, la región del golfo de Corinto se convertiría en época Alto Imperial en una zona de excepción en una Grecia despoblada y decadente.

Estas ciudades fueron agraciadas por los favores imperiales más que muchas otras, sin duda debido a sus importantes comunicaciones con la península Itálica, pero también porque supieron explotar su antiguo prestigio y el respeto que inspiró siempre su cultura y su pasado.

Ya desde el principio de su conquista y durante la época republicana, los conquistadores romanos sintieron una gran necesidad por conocer y reconocer los valores de la cultura griega, aspiración y deseo tan magnificamente descritos por Horacio en su famosa frase:

"Graecia capta ferum victorem cepit et artes intulit agresti Latio" (Horacio, Epist., 2, 1, 156-157).

Roma había aceptado la superioridad cultural de Grecia, o, al menos valoraba el prestigio de su historia y el peso de su civilización, de su tradición y de sus instituciones. El griego, no lo olvidemos, era la segunda lengua oficial del Imperio.

Es importante también recordar aquí que notables familias patricias romanas estuvieron vinculadas con ciudades griegas, a la vez que familias nobles greco-orientales tuvieron acceso al rango senatorial.

Este proceso se encuentra trasmitido por Plutarco, cuando describe las relaciones entre Roma y el mundo greco-helenístico en sus "Vidas Paralelas» dedicado y, en cierta forma, vinculando a notables figuras de la historia de Grecia y de Roma ${ }^{9}$.

9 Se ha utilizado la tradución de Plutarco editada por Gredos. Ver además: GEIGER, J.: «Plutarch'e Parallel Lives: The choice of Heroes», Hermes, 109, 1981, págs. 85 y ss. 
Tal vez, para justificar de algún modo el dominio romano sobre el oriente griego y la asimilación romana de la cultura helénica, el propio Augusto hacía descender la Gens lulia del héroe troyano Eneas, hijo de Venus, y con ello consideraban que habían alcanzado el derecho de ser incluidos en la Paideía griega. Muchos de sus actos iban encaminados a demostrar su asimilación y su inclinación más o menos ferviente por esta cultura ${ }^{10}$.

Se podrian citar muchos y significativos ejemplos del amor y la educació "a la griega" de importantes personajes de Roma, desde finales de la época republicana (Emilio Paulo, Claudio Marcelo, Escipión Emiliano...).

Tanto la familia Antonia, que tuvo una gran predilección por las provincias y los gustos orientales, como la propia familia Imperial Julio-Claudia demostraron sus preferencias y su respeto por la cultura griega aunque, a veces, ésta tuvo un tono más frío como la actitud de Tiberio o Calígula.

Augusto visitó Grecia y favoreció a varias ciudades, entre ellas, Atenas y Egina ${ }^{11}$.

Sus sucesores Tiberio y Calígula, fueron los príncipes Julio-Claudios más indiferentes a Grecia. Sin embargo, Claudio visitó Tesalia entre los años 10 y $11 \mathrm{~d}$. C. Muy posiblemente llegó a conocer el problema del empobrecimiento de Acaya y dispuso medidas para ello.

Se conocen, entre otros documentos, una carta a los Tasiotas para a regular cuestiones comerciales, además de asuntos de culto. La segunda está dirigida al gobernador de Acaya entre los años 52 y $53 \mathrm{~d}$. C., encargando las medidas oportunas para evitar el despoblamiento de Delfos. Se cedieron tierras comunales en barbecho debidamente parceladas para atraer colonos a la región. Este era un medio muy utilizado. Con frecuen-

10 Ferraty, J. L.: Philhellénisme et Imperialisme. Aspets idéologiques de la conquête romaine du Monde hellénistique. Roma, 1988, págs. 506 y ss.; García MorenO, L.: “Roma y los protagonistas de la dominación romana de Grecia en las Vidas Paralelas de Plutarco", Graecia Capta. Huelva, 1996, págs. 129-147.

11 Aunque es posible que Atenas no fue de las ciudades más favorecidas por Augusto, Agripa se preocupó por embellecer la ciudad, construyó el odeón, restauró el ágora y se reconstruyeron más de ochenta santuarios. Ver Bowersock, G. W.: Augustus And the Greek World. Oxford, 1965; Bowersock, G. W.: “Augustus on Aegina", Classical Quaterly, 14, 1964, págs. 120-121; OtlVIER, J. H.: «Roman emperors and Athens", Historia, 1981 págs. 412-423; Graindor, P.: Athènes sous Auguste. El Cairo, 1929; ibidem: Athènes de Tibére à Trajan, 1931; Sobre las visitas imperiales: Halfmann, H.: Itinerara Principum. Stuttgart, 1986, También: Geagan, D. J.: «Imperial Visits to Athens: The epigraphical Evidence", Actes du VI/19 Congr. Intern. Epigra. Grecque et Latine Atenas, 1982, Musée Epigraphique, 1984 págs. 69-78. 
cia estas tierras se cedían con propiedad plena, incluso con el derecho de trasmitirlas a los herederos ${ }^{12}$.

\section{NERÓN Y ACAYA}

De todos los emperadores Julio-Claudios, fue Nerón el que se mostró particularmente inclinado hacia los griegos y hacia la cultura griega, sobre todo al final de su principado.

Ya Schumann señaló el particular filohelenismo de Nerón, tan particular, que resulta imposible de definir en términos extrictamente políticos, pero que, sin duda marcarían su personalidad y su ideología política.

Su conducta fue calificada de extravagante por sus contemporáneos, como recogen las fuentes literarias Ello se debía en gran medida a sus gustos y a sus tendencias filohelenas. Nerón sin duda conoció, admiró y practicó notables manifestaciones de esta cultura de forma muy superior a muchos de sus contemporáneos. Tal vez su pasión por la música, la literatura, el teatro y los juegos atléticos contribuyeran de forma decisiva a su interés por las ciudades griegas, que, igualmente aficionadas, celebraban festivales y juegos desde época ancestral. La influencia de estas celebraciones se encuentra claramente en la institución de los Juegos "Juvenalia" y "Neronia", estos últimos inagurados precisamente en una ciudad de origen y tradición griega, Neapolis, en el año $60^{13}$.

Este filohelenismo de Nerón, no se limitaba ni a la Grecia geográfica, ni a la Grecia tradicional. Su amor por las artes, la cultura y el pensamiento griego no muestra preferencias entre el griego clásico o helenístico. Su sentido estético tampoco se mantuvo en unos límites precisos y encontró un marco adecuado en otros lugares del mundo helenístico lejanos del marco geográfico griego. Quiso visitar Alejandría (El texto de Suetonio parece confirmar que este viaje se realizó: Emprendió sólo dos viajes: uno a

\footnotetext{
12 Sobre Delfos, su decadencia y su relación con el gobierno de Roma ver: Poull.oux, J: “Delphes et les Romains", Stele, Homages à N. Kontoleón. Atenas, 1978, págs. 201 y ss.; Vatin, C.: Delphes à l'ópoque Impériale, Tesis de la Sorbona, 1965; FLACELIERE, R.: "Rome et les empereurs vus par Plutarque", L'Anti. Class., 32, 1963, págs. 28-47.

13 Sobre la conducta política y la ideología neroniana ver entre otros: ClZEK, E.: Lépoque de Néron et ses controverses idéologiques. Leiden, 1972, ibidem, Néron. París, 1982; Griffin, M. T.: Nero. The end of a Dynasty. Londres, 1987; Fernández URIEL, P. «Nerón y Neronismo. Ideología y mito", E. T. y F., Serie II, $n^{\circledR} 4$, 1991, págs. 199-222; ibídem, «Nero alter Apollo. La divinización del Princeps en la ideología neroniana", Héroe, semidioses y héroes. Primer encuentro-coloquio de ARYS. Madrid, 1992, págs. 159-173.
} 
Alejandría y otro a Acaya, Suetonio, Nerón, XIX, 1) y viajó con frecuencia a la Magna Grecia, en particular residió en Neapolis, ciudad muy querida, que visitó en momentos muy significativos: Allí tuvo lugar su primera representación. Allí buscó consuelo tras la muerte de su esposa Popea y allí quiso manifestarse popularmente en la visita del rey Tirídates de Armenia. También Neapolis le recibió en su vuelta triunfal de Grecia, donde permaneció un tiempo hasta conocer la rebelión de Vindex ${ }^{14}$.

\section{LOS ANTECEDENTES}

Este interés e inclinación de Nerón por las ciudades griegas fue demostrado públicamente desde época muy temprana, durante el principado de su antecesor, Claudio. Podría considerarse como antecendente de esta postura del césar su defensa de Rodas y su alegato, en griego, ante su padre adoptivo en favor de los rodios en el año $53 \mathrm{~d}$. C.

Esta isla había disfrutado de una privilegiada posición en el Imperio hasta que en el año 44, tras un penoso episodio de secesión, fueron crucificados algunos ciudadanos romanos. Debido a este incidente, Rodas, perdió gran parte de sus libertades y de sus exenciones fiscales. Apelaron los rodios a Roma, encontrando en el joven príncipe su mejor apoyo.

Una inscripción honrando a los embajadores que lograron traer una respuesta favorable de Claudio y sobre todo el informe de los buenos oficios de Nerón es el mejor testimonio de este suceso.

Son además importantes y notables testimonio de este evento, de su entorno político y de sus posibles consecuencias, el epigrama de Antifilio de Bizancio que celebra los buenos servicios de Nerón a Rodas comparando, significativamente, a éste como el propio dios Sol que envía sus bendiciones a los rodios como su patrono ${ }^{15}$, así como una emisión

14 Fernandez Uriel, P.: “La llegada de Tirídates de Armenia a Roma. Su contexto, transcendencia y significado". In memoriam J. Cabrera Moreno. Universidad de Granada, 1992, págs. 117-133.

15 Sobre este episodio: TACITO, ANNALES, XII, 58: «Se devuelve a los rodios su libertad, tantas veces suprimida y confirmada, según habian hecho méritos en las guerras exteriores o promovido sediciones externas", SUETONIO, Claudio, XXV, 3: "Despojó a los licios de la libertad, en castigo a sus querellas intestinas, devolviéndola, en cambio, a los rodios, como recompensa a su arrepentimiento por faltas pasdas"; Nerón, VII, 2: "Defendió en latín ante Claudio, cónsul a la sazón, a los habitantes de Bolonia y en griego a los de Rodas y a los troyanos", Sobre la Inscripción de Rodas: DION CASSIO, 60, 4; I. G. R. R., IV, 1124. Acrato, liberto de Nerón, tranquilizó a los rodios, confirmando la protección de éste sobre la isla cuando estaba recogiendo obras de arte para la Domus Aurea. PLINIO, N. H., 34; FABIA, Ph: “Néron et les Rhodiens", Revue de Philologie, 19, 1896, págs. 218 y ss. 
monetaria rodia que incide en el tema, representando a Nerón con la aureola del sol.

Nerón protegió siempre a los rodios y Rodas figuró siempre como uno de sus lugares preferidos.

La representación y comparación de Nerón con el sol entre los rodios nos lleva a otra importante vinculación de Nerón con las ciudades griegas relacionada con su propia doctrina política que los griegos supieron hábilmente utilizar.

Siguiendo la doctrina senequista, Nerón se comparaba con el sol, como protector del Universo, concepto que ya se subrayaba en Rodas. Como Nerón-Helios, igualmente se vinculaba con Apolo, el dios de las artes y tañedor de la lira. Ello como apunta Maurice Sarte, sin duda no podía sino agradar a los griegos ${ }^{16}$.

También Ch. Picad no dudaba en calificar las aspiraciones neronianas como una «revolución político-cultural en la que el mismo césar llegó a participar activamente». Añade P. Petit que el Neronismo se encuentran un programa político y una ideología estética dirigidas por el propio Nerón. Desde luego, esta preocupación por la estética y la creatividad artística en todos sus niveles es una de las características más sobresalientes del neronismo, y tal vez, es en los expecáculos y en las competiciones y juegos donde encontró uno de sus principales medios ${ }^{17}$.

Considerando este importante aspecto de la política neroniana, unido a este nuevo brote de su filohelenismo, los griegos pudieron albergar esperanzas de beneficios y de protección.

Pero este vinculación fue recíproca: No sólo por el prestigio cultural, sino por la propia educación y afición de los helenos, el césar quería vivir y participar con ellos sus aficiones artísticas y estéticas, "pues sólo los griegos eran dignos de compartir su arte":

Según el relato de Suetonio fueron los propios griegos y sus tradicionales representaciones quienes convencieron a Nerón de realizar su viaje a Acaya:

SARTE, M.: El Oriente Romano. Madrid, 1994, págs. 246.

17 PICARD, Ch.: Auguste et Néron. Le secret de l'Empire. París, 1962, pág. 62. Según Picard: "Nerón es el único soberano de la Historia que quiso gobernar como artista (no como mecenas) e imponer a su época en todos los campos y de una manera poco realista, concepciones púramente estéticas...", pág. 193; también Frazer; R. M. Jr: “Nero, the artist-criminal», Classical Journal, 1966, págs. 17 y ss.; PETIT, P.: Histoire Géneral de l'Empire Romain, I. París, 1974 págs. 109; FERNÁNDEZ URIEL, P.: «Nerón y Neronismo...», op. cit., pág. 205. 
“No le bastó haber demostrado en Roma su habilidad por lo que marchó, como ya hemos dicho, a mostrarla a Acaya, movido principalmente por la razón siguiente: Las ciudades en las que hay establecidos concursos de música, aconstumbraban a mandarle coronas de todos los vencedores y tanto le placía este homenaje, que los diputados que venían a presentárselas, no sólo eran los primeros a quienes recibía en sus audiencias, sino que los admitía en sus comidas particulares. Habiéndole rogado, cierto dia, alguno de ellos que cantase en la mesa y prodigando toda clase de elogios dijo que "sólo los griegos sabian escuchar y eran dignos de su voz". Partió pues sin detenerse y desembarcando en Casiope, cantó delante del altar de Jupiter Casio", Suetonio, Nerón, XXII.

\section{Era el mes de abril del año 66.}

Nerón estuvo en Grecia unos catorce meses, es decir, desde septiembre del año 66 hasta diciembre del año 67.

Es importante la observación de E. Cizek, sobre la actitud de la marcha de Nerón a Grecia no como Mumio, ni como Flaminino, ni tan siquiera como Augusto o Agripa puesto que Nerón no se dirigió con un ejército ni en un afán de conquista, sino para compartir un mismo ideal cultural, además de otros objetivos políticos "su séquito no estaba compuesto de un ejército sino de políticos, artistas y servidores, entre los que se contaban los cinco mil Augustani” ${ }^{18}$. El quería ser proclamado "Victor», no por su fuerza militar, sino por la persuasión de su persona y por su voz.

La actividad más señalada durante su estancia en Grecia es sin duda su participación en los grandes agones griegos, iniciada en el mes de octubre del año 66, participando en los juegos Píticos, Istmicos, Nemeos y Olímpicos, declarado vencedor en todos ellos, además de realizar representaciones en las ciudades de Argos y Lerna ${ }^{19}$.

La actitud y actuaciones de Nerón han sido narradas con duras críticas por autores como Suetonio (XXII y XXIII) y Juvenal ${ }^{20}$.

18 Clzek, E.; Lépoque de Néron..., op. cit., pág. 216; Sobre los Augustani: TACito, Annales, XIV, 15, 9; SUETONIO, Nerón, XX, 6; MOURGES, J. L.: "Les Augustians et l'expérience théatrale néroniene", Revue des Études latines, 66, 1988, págs. 156-179; GATTI, CL.: "Gli Augustiani», Estudi neroniani, II, 1976-77, págs. 103-121; Fernández URIEL, P.: “Nerón y Neronismo...», op. cit., págs. 209-210.

19 Estudiado por Schumann, G., op. cit., págs. 69; LeVI, M. A.: Nerone e soui tempi. Milán, 1949, págs. 209; ClzEK, E., op. cit., págs. 214-215. Nota, 3, en la que realiza una división de las actuaciones y etapas del viaje.

20 «A partir de entonces se le vio tomar parte en todos los certámenes de los artistas, con cuyo objeto reunió en un mismo año los expectáculos ordinarios que se daban en largos intervalos;quiso que se repitiesen algunos y ordenó, contra la constumbre, abrir en Olimpia un concurso 
No nos detendremos en analizar la conducta del emperador en estas competiciones, ni en la incidencia que sin duda tuvo en la opinión pública, tanto de Roma como en el resto del Imperio.

Aún siendo, sin duda, su participación en los Juegos y competiciones tan significativas y representativas de su ideología, de su política y de su propia personalidad, estas representaciones, exhibiciones y victorias del "princeps" no deben considerarse la actividad más decisiva de su visita a las ciudades de Acaya, y ni mucho menos, la única.

Nerón demostró que su interés y afecto por Grecia también abarcaba otros aspectos de los que los griegos se encontraban deficitarios.

Se tomaron medidas de carácter económico y de ayuda a la provincia, como los subsidios de cuatrocientos mil sestercios que se donó a los pitios, o el millón de sestercios que Nerón donó a los jueces olimpicos, «Hellanodikai" que siempre se han considerado en parte soborno, para que le fuera favorable el oráculo pítico y, en parte, como recompensa a los jueces por sus victorias. (Dion Cassio, LXIII, 14, 1-2).

Desde Corinto, que como capital de la provincia romana tuvo un mayor protagonismo en la visita del emperador, Nerón realizó otras intervenciones. Llevó a cabo la dirección de las operaciones militares contra la insurrección judia, enviando al general Vespasiano para ocuparse de la represión contra ésta sedición en la primavera del año 67, a pesar de como cuenta Suetonio, Vespasiano había caído en desgracia ante el césar, porque, acompañándole en su séquito a Acaya, se quedaba dormido con frecuencia en las actuaciones del propio emperador ${ }^{21}$.

No fueron de menor importancia otras medidas administrativas efectuadas en la propia ciudad de Corinto entre Noviembre del año 66 a abril del 67 realizó notables proyectos de construcción de edificios, entre ellos la restauración del teatro que hasta entonces permanecía en ruinas.

de música. Nada pudo ni apartarle ni distraerle de este género de placer y habiéndole informado su liberto Helio que los asuntos de Roma requierian su presencia allí contestó: "En vano me escribes queriendo que regrese prontamente, mejor es que desees que vuelva digno de Nerón"". SuETONiO, Nerón, XXIII.

Las palabras de Juvenal son durísimas: “Estas son las obras de un principe que se deleita en prostituirse cantando sobre tabladillos, tentado por el opio de la corona griega", JuVENAL, Satiras, L. III, Sat. VIII. vv. 224-226.

21 Suetonio, Vespasiano, IV, ; F. Josefo, Bel. lud., 3, 1; Tacito, Histor, 5, 10, 3. Los juegos Ístmicos que se celebraban en Corinto, se realizaban cada dos años, en primavera, en el santuario de Poseidón, cerca del Istmo. Fue L. Castricio Regulo, duumvir de la colonia quien restauró los juegos que habían sido trasladados a Sición. Con Nerón recuperaron grandiosidad. PAUSANIAS, II, 2; Roux, G.: Pausanias en Corinthe, págs. 91-102; Le Glay, M.: Villes, temples et sactuaires, págs. 62-78. 
Pero, sobre todo, destaca la empresa que inició Nerón a finales del mes de septiembre de aquel año, para realizar la construcción del canal en el istmo de Corinto que abriría y facilitaría la comunicación entre ambos mares.

Las fuentes califican esta empresa como uno más de los caprichos del emperador, motivado por un deseo de vanidad y de imitar la gloria de los "Basileis" del pasado.

Es posible que esta afirmación no fuera muy descaminada y el deseo de tratar de emular a los basileis helenísticos moviera gran parte de su intencionalidad. Prueba de ello, pudiera ser su intención de denominar a la península «isla de Nerón» cuando se hubiera terminado el canal ${ }^{22}$.

Pero ello no resta el mérito de que Nerón hubiera decidido a llevar definitivamente a cabo una de los más transcendentales proyectos de ingeniería, establecido dentro de un plan de economía y de construcciones del gobierno de Roma. Los estudios actuales consideran importantes y valiosos los trabajos de ingeniería que el emperador mandó comenzar para logra de forma definitiva este canal que había sido la aspiracion de los griegos desde muy antiguo:

Sin duda la apertura de este canal habría favorecido las relaciones comerciales, la comunicación y, en fin, habría dado un nuevo empuje a la economía de la provincia, por lo que era lógico que estuviera contemplado en los proyectos de Roma propuestos para mejorar las condiciones de una Grecia pobrecida y decadente, que, además favorecería la comunicación y el comercio entre el resto de las provincias del Este, como hacen notar los estudios de M. Canavesi y E. Cizek.

El propio Julio César se había dado cuenta de la importancia de este paso que tanto favorecía el comercio entre Oriente y Occidente y facilitaba que Roma pudiera controlar e incluso aumentar en lo posible las relaciones diplomáticas y económicas con los paises orientales. (Suetonio, César, XLIV).

Más adelante, Calígula intentó iniciar de nuevo el proyecto: «Pero ante todo quiso abrir el istmo de Acaya, para lo cual había ya enviado un centurión primipilario a que lo midiese con exactitud" (Suetonio, Cayo Calig. XXI, 4).

El viejo proyecto fue retomado por Nerón.

22 Según Holleaux, M. En Études d'ephigraphie et d'histoire grecques. París, 1938 págs. 181, $n^{2} 4$; PsEUdo LucIano, Nero, 2-3; Asi narra Suetonio el inicio de las obras para la construcción del canal: "En Acaya se propuso abrir el istmo:arengó a los pretorianos para exhortarlos a aquella gran empresa; hizo que una trompeta diese la señal para empezar y él mismo descargó el primer golpe de azadón y se cargó al hombro una esportilla llena de tierra". SuETONIO, Nerón, XIX, 3. 
El propio Filostrato estima que la construcción del canal era el acto más importante de su principado ${ }^{23}$.

Sin embargo su realización tropezaba con toda clase de dificultades. La primera era la suposición de la desigualdad de niveles entre las aguas de los mares que separaba el istmo, lo cual podía provocar inundaciones y catástrofes.

En segundo lugar, existían temores y supersticiones en torno al lugar de la apertura del canal. Los trabajadores huian de su labor porque se decía que se oían gemidos cuando se golpeaba la tierra.

La gran donación de Nerón a las ciudades griegas de Acaya se realizó también en Corinto, tras los Juegos Istmicos, con la concesión de ciertos privilegios administrativos y fiscales a dichas ciudades.

Algunos autores opinan que ocurrió durante los Juegos. Por ello A. Momigliano considera este anuncio de libertades tendría lugar el 28 de noviembre del año 66, teniendo en cuenta que los juegos ístmicos se celebraban cada dos años en tal fecha, pero es muy posible que este discurso de Nerón fuera pronunciado despues de las celebraciones de los Juegos, en torno al verano del 67 d. C. ${ }^{24}$.

Contamos pra este estudio con varios testimonios literarios y epigráficos que concuerdan en dos aspectos fundamentales.

Tal fue la satisfación y recíproca identificación de Nerón con los griegos de Acaya, donde fue aclamado, encontrando un "climax" que se correspondía con sus aspiraciones y podía desarrollar su aficiones, que anunció personalmente que venía a restituir la libertad a las ciudades de Acaya y conceder una serie de inmunidades (Beneficia) fiscales.

Plinio el Viejo y Dion Casio nos cuentan que Nerón concedió la libertad a toda la provincia de Acaya. "Universae Achaiae libertatemDomitius Nero dedit». (Plinio, N.H., 4, 10, 2, Dion Casio, LXIII, 11. 1). Pausanias coincide con ambos en gran parte en su relato:

«Pasado un tiempo, el Imperio de los romanos pasó a Nerón que puso en libertad a todos los griegos y compensó de esto al pueblo de los romanos con la entrega de la rica isla de Cerceña en vez de Grecia.

23 Canavesi, M.: Nerone, Milán, 1945 pág. 210; Cizek, E., op. cit., pág. 216; Filostrato, Vita Apol., 5, 7 .

24 Momigliano, A. Nero, op. cit., págs. 735; Contra ests teoría se encuentra la de E. Cizek, siguiendo los testimonios epigráficos Cizek, E., op. cit., pág. 217; Gallivan, P.: "Nero's liberation of Greece". Hermes, 101, 1973, págs. 23 y ss. 
Considerando yo este hecho de Nerón me pareció muy bien el dicho de Platón, hijo de Aristón (Republ., 491 E) de que las injusticias mayores y enormes no se cometen por los hombres vulgares, sino por los de alma noble, dañada por una mala educación". Pausanias, Descrip. Grecia, L. II, VII, 17, 3).

Según el texto del discurso pronunciado por el emperador en Corinto, se precisa claramente que «tanto los griegos de Acaya como los habitantes del Peloponeso recibirían la libertad".

Esta concesión de libertad está constatada por tres grupos de testimonios importantes:

- La triple documentación estudiada por M. Holleaux: La primera es una convocatoria del propio emperador a los griego en Corinto, la segunda es el discurso pronunciado por el emperador donando esta «libertad" y la $3^{\mathrm{a}}$ un decreto en honor de Nerón votado por la ciudad de Acraphía tras dicha liberación, que se conserva en la estela de Karditza.

- La información que completa el texto de Plutarco ${ }^{25}$.

- Los testimonios de Pausanias y Suetonio sobre la pérdida de estas libertades tras la ascensión al poder del emperador Vespasiano:

"No disfrutaron los griegos de esta concesión, pues en tiempos de Vespasiano, sucesor de Nerón, se lanzaron a la guerra civil, y Vespasiano les volvió a someter al tributo y a la obediencia del pretor, diciendo que los griegos habian perdido la constumbre de la libertad

Estos son los sucesos tales como los he hallado", Pausanias, Descrip. Grecia, L. II, VII, 17, 3-5

"Privó de la libertad a Acaya y a Licia, Rodas, Bizancio y Samos, que redujo a provincias romanas, así como también a Tracia, Cicilia y Comagene, gobernadas hasta alli por reyes", Suetonio, Vespasiano, VIII, 6.

Este episodio suele aceptarse sin realizar un análisis más detenido sobre el carácter y el alcance de estas concesiones de Nerón. Es más, no se puede llegar a conocer en profundidad este acontecimiento sin hacer un estudio más intenso sobre en que consistía y qué abarcaba esta libertad.

25 I. L. S., 8794;SIG, 814; AJ. 56; ChaRLESWORTH, N. 2; ARS; 180 LR. pág. 394; SMALLwOOD, E. M.: Documents Illustrating the Principates of Gaius, Claudius and Nero, Cambridge, U. P., 1967, $n^{9} 64$ págs. 35-37; Holleaux, M.: «Discours de Néron prononcé à Corinthe por rendre aux Grecs la liberté", Bulletin de Correspondance Hellénique, $\mathrm{n}^{2} 12,1888$, págs. 510 y ss.; ibidem: Études d'ephigraphie et d'histoire grecques. París, 1938, págs. 181, $n^{9} 4$; Warmington, B. H.: Nero: Reality and Legend. Londres, 1969, págs. 117-118. 
Las fuentes literarias no son precisamente muy explícitas a la hora de informar cuáles fueron exactamente estas cesiones del Príncipe. Pecan de imprecisas, pero citan con cierta claridad dos concesiones imperiales que son un auténtico privilegio en el dominio de Roma, que perdieron, en parte con Galba (Dion Casio, 63, 14, 1) y definitivamente bajo Vespasiano:

- La liberación de encontrarse bajo el dominio directo del pretor.

Acaya pasó de ser una provincia senatorial a ser provincia Imperial, dependiendo directamente del emperador.

- El indulto o eximición de las cargas fiscales.

Los griegos se verían liberados en primer lugar del tributo o impuesto directo denominado "Tributum capitis" o "Capitatio", es decir, el tipo de tributum establecido por Augusto sobre la persona física, considerado como una especie de servidumbre y sólo remitido a los no ciudadanos.

$Y$ hasta es posible que, además fueran también eximidos de un segundo tributo "Tributum soli", sobre la propiedad de la tierra, que en el caso de los comerciantes, (Homines negotiantes) equivalía a "Aurum Negotiatorun", de acuerdo con las ganancias de sus negocios ${ }^{26}$.

Es decir, no gozarían en modo alguno de una total inmunidad fiscal, sino de los tributos directos, de los que estaban eximidos los ciudadanos "optimo iure", cuya carga tributaria recaía sobre los habitantes no ciudadanos de las provincias del Imperio.

Así, Nerón aunque no asignó la plena ciudadanía a los griegos ciudadanos de Acaya, si pudo concederles ciertos privilegios privativos de ésta como la inmunidad fiscal relativa a los impuestos o tributos directos, equiparándose en tal sentido a los ciudadanos romanos, a ello se refiere la trnscripción de $\mathrm{M}$. Holleaux "Los griegos pudieron disponer de igualidad administrativa y económica como los romanos, sin recibir la cualidad de ciudadanos".

Ello significaría que, aunque estos gozaran de las mismas exenciones fiscales que los ciudadanos romanos, es decir, estaban libre de los impuestos directos, como los ciudadanos romanos no se salvaban de los impuestos indirectos, los denominados "vectigalia", los "Portoria", o "Aurum vicesimarium», los cuales tenían diversas clases y asignaciones ${ }^{27}$.

26 GarzettI, A.: "Aerarium e Fiscus sotto Augusto; Storia di una questione in parte di nomi", Athenaeum, XXXI, 1953, págs. 298 y ss.; JONES, A. H. M.: "Aerarium and the Fiscus", J.R.S. XL. 1950 , págs. 25 y ss.

27 Sobre el fisco romano ver entre otros: BRUNT, P. A.: "The Fiscus and its Development", J.R.R., 56, 1966, págs. 75-85; FERNANDEZ URIEL, P.: "Algunas percisiones sobre el sistema fiscal romano", Espacio, Tiempo y Forma, S. II, 8, 1995, págs. 159-181. 
A pesar de ello, esta exención de unas importantes cargas fiscales era una necesaria medida económica, tal vez ya concebida dentro de un plan general para conseguir una mejor recuperación de esta provincia empobrecida del imperio.

Todas estas medidas eran sin duda importantes y beneficiosas. Contribuyeron a conseguir resultados ideológicos, culturales y políticos de gran consideración.

Era éste un acontecimiento que volvía a repetirse en los Juegos İstmicos como refiere Plutarco, en su narración sobre Tito Quinto Flaminino:

"Ocurrió dos veces este mismo suceso en la ciudad de Corinto, porque hallándose en ella Tito y despues igualmente Nerón en nuetra edad, a la sazón de celebrarse los juegos istmicos, declararon a loa griegos libres e independientes:aquel por medio de pregonero, como dejamos dicho, pero Nerón, por sí mismo, hablando en la plaza al concurso desde la tribuna, lo que, como se ve, fue mucho más adelante». Plutarco, Vita Flaminino, XII.

Este general romano era, según la descripción de Plutarco, amante de la cultura griega, hablaba griego y tenía la típica virtud helénica de la filantropía. Los favores y regalos concedidos a los griegos no sólo se realizan como tal, sino emulando a los reyes helenísticos ${ }^{28}$.

Ambos acontecimientos narrados como paralelos por Plutarco, tienen importantes coincidencias tanto ideológicas como políticas y culturales, hasta tal punto que esta famosa proclamación de la «libertad" de los griegos por Nerón en Corinto es calificada acertadamente por L. Garcia Moreno como un hecho tan excepcional que "constituyó el punto culminante de una pretendida helenización del poder Imperial» ${ }^{29}$.

Al recordar Plutarco la proclamación de Nerón y compararla con la de Flaminio, tratado este último como modelo de las virtudes romanas, tal vez intentara atraer la atención y reclamar del gobierno imperial y del propio emperador, un tratamiento más favorable para las ciuda-

28 Garcia Moreno incide que Flaminio da muestras de una "Philotimia" y "Philodoxia". Para L. García Moreno T. Q. Flaminino también trataba de asemejarse al héroe y basileus por excelencia: Alejandro Magno, aspiración que tuvieron los príncipes romanos, incluido Nerón. GaRcía MORENO, L.: "Roma y los protagonistas de la dominación romana en Grecia", Graecia capta, Huelva, 1996, págs. 129-148; Sobre la política de los emperadores romanos y su imitación de Alejandro: KIENST, D.: «Augustus und Alexander", Gymnasium, 76, 1969 págs. 430-456; Garcia MoREnO, L.: "Alejandro magno y la política exterior de Augusto", en J. M. Croisille (ed) Neronia, IV, Alejandro Magno, modelo de los emperadores romanos. Brusęlas, 199; BADIAN, E.: Titus Quinctus Flaminius Philohallenism and Realpolihk, Cincinnati, 1970.

29 Garcia Moreno, L., op. cit., pág. 146. 
des griegas de su tiempo, que habían perdido la ansiada libertad antes concedida.

Descubrimos unos alcances políticos notables para la propaganda y la publicidad oficial de la ideología neroniana. Así ciertos autores griegos, aunque no dejaron de calificar de forma negativa la figura de Nerón en otras manifestaciones de su conducta, por lo general, consideraron la liberación de las ciudades de Acaya, como uno de los sucesos más acertado y beneficioso en su trayectoria y para su figura política.

Filostrato escribió que Nerón restituyó la libertad a los griegos, exhibiendo una gran prudencia y moderación y describió este acto como uno de los que rejuveneció e impulsó a las ciudades, pues instituyó en ellas la paz, la concordia, y el orden que no habían logrado en mucho tiempo. También Pausanias y Plutarco le calificaron como el libertador de Grecia.

Tespies de Soli le consideró "como alguien a quien los dioses miraron con amabilidad pues habia liberado a los griegos, tan queridos por ellos» ${ }^{30}$.

Escritores como Filostrato y Plutarco que, en su ideología filosenetorial, despreciaban las actuaciones y exhibiciones de Nerón, consideraron convenientes y acertadas sus disposiciones en Acaya, promovidas no sólo por su simpatía y atracción por Grecia y lo que significaba, sino además proyectadas en un programa económico y político.

En este contexto se entiende como es aclamado por el gran sacerdote del culto Imperial:

«El más grande césar, filoheleno, Nerón Zeus, dios y gran libertador de Acaya”.

La emperatriz Estatilia Mesalina es denominada "Thea Sebastés».

El entusiamo y el reconocimiento de los griegos, según $E$. Cizek fue sincero y demostraron su gratitud a Nerón.

La Hélade, como segundo polo de cultura del Imperio podía influir en la propaganda oficial romana y, desde luego en la mitad oriental del Imperio. Cizek, en su momento, propuso la posibilidad de que el Princeps llegara a pensar en la ocasión de realizar una cierta descentralización del Imperio, prefigurando una nueva Constantinopla en torno a la vieja provincia Acaya, desde donde pudiera mantener una corte a modo de las

30 Filostrato, Vita Apol., 5, 36; Pausanias, Descrip. Graec., 9, 27, 4; Plutarco, Moral, 505C y 56F. Recogido por Griffin, M. T., Nero the end of a Dynasty, op., cit., pág. 211. 
provincias Helenisticas, teoría que parece algo precipitada para su época ${ }^{31}$.

Si es cierto que con su conducta y sus favores en Acaya, buscaba una popularidad favorable en la parte helenística y oriental del imperio, donde, por añadidura, se identificaba personal e ideológicamente.

Tal vez Nerón esperaba alargar su permanencia en Acaya, tal vez intentaba, al menos, prolongar ésta por otras provincias de ideología y corte helenístico como Siria o Egipto.

Su regreso repentino tras la rebelión de Vindex acabó con su principado, su vida y su propia dinastía, finalizando esta hermosa etapa, aunque permaneció el recuerdo de Nerón, de las buenas relaciones mutuas y de la identificación entre este polémico príncipe y las ciudades de Acaya durante mucho tiempo. 